\title{
Peran Bidan dalam Konseling Awal Kontrasepsi Suntik DMPA
}

\author{
Farida Aryani ${ }^{1}$
}

${ }^{1}$ Sekolah Tinggi IImu Kesehatan Alma Ata Yogyakarta

Jalan Ringroad Barat Daya No 1 Tamantirto, Kasihan, Bantul Yogyakarta

\begin{abstract}
Abstrak
Pertumbuhan penduduk Indonesia yang mencapai 1,3\% tiap tahun menjadi permasalahan kependudukan. Konseling program Keluarga Berencana diperlukan sebagai salah satu solusi permasalahan tersebut. Penelitian non eksperimental dengan disain observasional yang menggunakan pendekatan shot model ini bertujuan Mengetahui peran bidan dalam konseling awal kontrasepsi suntik DMPA di Puskesmas Mergangsan, Yogyakarta 2012. Populasi penelitian ini adalah ibu-ibu yang melaksanakan kunjungan pertama dan kedua kontrasepsi suntik DMPA. Hasil penelitian ini adalah $71,1 \%$ bidan berperan dengan baik dalam konseling awal kontrasepsi suntik DMPA.
\end{abstract}

Kata Kunci: peran bidan, kontrasepsi, DMPA

Info artikel:

Artikel dikirim pada 19 agustus 2013

Artikel diterima pada 19 agustus 2013

\section{PENDAHULUAN}

Masalah kependudukan di Indonesia yang utama adalah jumlah penduduk yang begitu besar dengan laju pertumbuhan penduduk $1,3 \%$ tiap tahunnya. Dan harus diturunkan menjadi $1,14 \%$ per tahun, jika tidak maka pada tahun 2050 Indonesia akan mengalami kenaikan penduduk hingga $231,3 \%$. Dilihat dari segi kuantitas penduduk Indonesia cukup besar tetapi dari sisi kualitas, melalui Indeks Pembangunan Manusia (IPM) kondisi Indonesia sangat memperihatinkan karena dari 117 negara Indonesia di posisi 108. Tingginya laju pertumbuhan yang tidak diiringi peningkatan kualitas penduduk ini membuat pemerintah terus melakukan upaya penanganan yaitu dengan program KB (Keluarga Berencana). ${ }^{1}$

Pasangan Usia Subur (PUS) berjumlah 549.894 di DIY pada tahun 2011. Di kota Yogyakarta, PUS berjumlah 46.755 . Peserta KB baru di DIY pada tahun 2011 mempunyai target 54.182, sedangkan pencapaiannya 55.781 (102,95\%). Peserta baru kontrasepsi IUD mempunyai target 9.261 , sedangkan pencapaiannya $11.583(125,07 \%)$, target MOW 1.670 pencapaiannya $1.620(97,01 \%)$,target kondom 5.472 pencapaiannya $5.469(99,95 \%)$, target implant 4.950 pencapaiannya $4.970(100,40 \%)$, target suntik 27.001 pencapaiannya $26.891(99,59 \%)$ dan target pil 5.288 pencapaiannya $4.890(92,47 \%){ }^{2}$
Peserta KB baru dengan kontrasepsi suntik di DIY pada tahun 2011 berjumlah 26.891. Di kota Yogyakarta peserta baru kontrasepsi suntik berjumlah paling sedikit yaitu $1.481(59,24 \%)$ dibandingkan dengan kabupaten lain, diantaranya di Kulon progo $3.629(100,44 \%)$, Gunung kidul $6.556(98,13 \%)$, Sleman $7.593(103,38 \%)$, dan di Bantul 7.632 $(111,22 \%)^{2}$

Program KB merupakan program yang mendunia. Dengan adanya kesepakatan ICPD (Intrnational Conference On Population and Development) pelayanan KB dikaitkan dengan upaya mencegahan dan mengatasi masalah kesehatan reproduksi, misalnya masalah kematian ibu ${ }^{3} . K B$ merupakan program yang berfungsi bagi pasangan yang menunda kelahiran anak pertama, menjarangkan anak atau membatasi jumlah anak yang diinginkan sesuai dengan keamanan medis ${ }^{4}$. Dalam MDGs (Millenium Development Goals) tujuan yang ke-5 pada target $5 \mathrm{~b}$ disebutkan bahwa tujuan MDGs untuk mencapai dan menyediakan akses kesehatan reproduksi untuk semua pada tahun 2015 yaitu dengan penggunaan kontrasepsi pada wanita usia 15 sampai 49 tahun ${ }^{5}$.

Dampak tidak menggunakan alat kontrasepsi terhadap perencanaan kehamilan bagi ibu yaitu penurunan kesehatan mental dan sosial yang dimungkinkan oleh adanya waktu yang kurang untuk 
mengasuh anak dan perbaikan kesehatan tubuh terganggu karena kehamilan yang berulang kali dalam jangka waktu yang terlalu pendek.Bagi anak tidak mendapatkan perhatian, pemeliharaan, dan makanan yang cukup karena kehadiran anak tersebut tidak diinginkan dan direncanakan.Gangguan menstruasi yang dialami oleh akseptor kontrasepsi Suntik DMPA seringkali memberikan dampak psikologis dan perasaan khawatir dengan efek samping tersebut ${ }^{6}$.

Bidan merupakan tenaga kesehatan yang memiliki posisi yang strategis dalam meningkatkan kesejahteraan ibu, bayi, dan balita.Salah satu peran bidan adalah konseling.Bidan adalah ujung tombak pembangunan keluarga sejahtera dari sudut kesehatan dan pemberdayaan lainnya.Karena itu, sebagai ujung tombak dalam bidang kesehatan, bidan dituntut untuk berperan memberi pertolongan dini atau memberi petunjuk dalam pelayanan kesehatan ${ }^{7}$.

Berdasarkan studi pendahuluan yang telah dilakukan peneliti di Puskesmas Mergangsan, dari hasil wawancara langsung responden menyatakan bahwa kurang mengerti dengan efek samping kontrasepsi suntik DMPA, dan ada yang menyatakan kurang mengerti dengan kelebihan dan keterbatasan kontrasepsi suntik DMPA.Dari studi pendahuluan tersebut dapat diketahui bahwa bidan belum menjelaskan secara lengkap informasi saat konseling awal kontrasepsi suntik DMPA.Pasien tidak pernah diberi lembar evaluasi kineja bidan, sehingga kinerja bidan kurang pemantauan. Jumlah bidan di Puskesmas Mergangsan khususnya dibagian poli KIA adalah 5 orang, sedangkan jumlah pasien kurang lebih 10 orang setiap bulan untuk kunjungan baru kontrasepsi suntik DMPA. Oleh karena itu peneliti merasa tertarik untuk melakukan penelitian tentang peran bidan dalam konseling awal kontrasepsi suntik DMPA.

\section{BAHAN DAN METODE}

Jenis penelitian ini merupakan penelitian observasional.Jenis penelitian ini dengan metode kuantitatif dan didukung dengan metode kualitatif. Pendekatan waktu yang digunakan adalah one shot model.Metode kuantitatif digunakan untuk mengetahui persentase besarnya peran bidan dalam konseling awal kontrasepsi suntik DMPA, sedangkan metode kualitatif dengan metode wawancara mendalam dirumah responden untuk mendapatkan keterangan secara lisan dari informan tentang peran bidan dalam menerapkan langkah-langkah konseling kontrasepsi suntik DMPA.

Sampel pada penelitian ini berjumlah 30 orang, yaitu ibu-ibu yang melakukan kunjungan pertama dan kunjungan ke dua kontrasepsi suntik DMPA. Sampel untuk data kualitatif berjumlah 2 ibu yang melakukan kunjungan pertama atau kunjungan ke dua kontrasepsi suntik DMPA dan seorang bidan.

\section{Hasil dan Pembahasan}

Karakteristik responden dalam penelitian ini digambarkan berdasarkan pendidikan, umur, pekerjaan dan kunjungan suntik DMPA.Distribusi frekuensi karakteristik responden berdasarkan pendidikan, umur, pekerjaan dan kunjungan suntik DMPA dapat dilihat pada Tabel 1.

Tabel 2. Berdasarkan Pendidikan, Umur, Pekerjaan dan Kunjungan Suntik DMPA

\begin{tabular}{lll}
\hline \multicolumn{1}{c}{ Karakteristik Responden } & Frekuensi & $\%$ \\
\hline SD & 1 & 3,3 \\
SMP & 8 & 26,7 \\
SMA & 19 & 63,3 \\
D3 & 2 & 6,7 \\
\hline Total & 30 & 100 \\
\hline$<20$ tahun & 3 & 10 \\
$21-25$ & 6 & 20 \\
$26-30$ & 18 & 60 \\
$31-35$ & 3 & 10 \\
\hline Total & 30 & 100 \\
\hline Swasta & 16 & 53,3 \\
PNS & 2 & 6,7 \\
Tidak bekerja & 12 & 40 \\
\hline Total & 30 & 100 \\
\hline Kujungan pertama & 19 & 63,3 \\
Kunjungan Ke dua & 11 & 36,7 \\
\hline Total & 30 & 100 \\
\hline
\end{tabular}

Sumber : Data Primer, diolah 2012

Berdasarkan hasil karakteristik responden di atas, pendidikan responden paling banyak adalah SMA yaitu 19 responden (63,3\%). Umur responden yang terbanyak adalah usia 26-30 tahun yaitu 18 orang $(60 \%)$. Pekerjaan responden yang terbanyak adalah wiraswasta yaitu 16 orang (53,3\%). Kunjungan suntik DMPA yang terbanyak adalah kunjungan yang pertama yaitu 19 orang $(63,3 \%)$.

Peran bidan dalam konseling awal kontrasepsi suntik DMPA di Puskesmas Mergangsan, Yogyakarta dapat dilihat dari Tabel 2.

Berdasarkan tabel 2 dapat diketahui bahwa peran bidan menyapa dan mengucap salam dalam kategori baik yaitu $76,7 \%$. Peran bidan menanyakan informasi klien dalam kategori baik yaitu 83,3\%. Peran bidan menguraikan informasi alat kontrasepsi dalam kategori baik yaitu $73,3 \%$. Peran bidan membantu klien menentukan pilihan dalam kategori baik yaitu 
Tabel 2. Peran Bidan dalam Konseling Awal Kontrasepsi Suntik DMPA

\begin{tabular}{|c|c|c|c|}
\hline No Peran Bidan & Kategori Penilaian & Jumlah (orang) & $\%$ \\
\hline \multirow{3}{*}{ 1. Menyapa dan Mengucap Salam } & Baik $(76-100 \%)$ & 23 & 76,7 \\
\hline & Cukup (56-75\%) & 7 & 23,3 \\
\hline & Kurang $(<56 \%)$ & 0 & 0 \\
\hline \multirow[t]{3}{*}{ 2. Menanyakan Informasi Klien } & Baik (76-100\%) & 25 & 83,3 \\
\hline & Cukup (56-75\%) & 5 & 16,7 \\
\hline & Kurang $(<56 \%)$ & 0 & 0 \\
\hline \multirow[t]{3}{*}{ 3. Menguraikan Informasi Alat Kontrasepsi } & Baik (76-100\%) & 22 & 73,3 \\
\hline & Cukup (56-75\%) & 5 & 16,7 \\
\hline & Kurang $(<56 \%)$ & 3 & 10 \\
\hline \multirow[t]{3}{*}{ 4. Membantu Klien Menentukan Pilihan } & Baik (76-100\%) & 21 & 70 \\
\hline & Cukup (56-75\%) & 7 & 23,3 \\
\hline & Kurang $(<56 \%)$ & 2 & 6,6 \\
\hline \multirow[t]{3}{*}{ 5. Menjelaskan Alat Kontrasepsi Pilihan Klien } & Baik (76-100\%) & 18 & 60 \\
\hline & Cukup $(56-75 \%)$ & 8 & 26,7 \\
\hline & Kurang $(<56 \%)$ & 4 & 13,3 \\
\hline \multirow[t]{3}{*}{ 6. Menjelaskan Kunjungan Ulang } & Baik (76-100\%) & 19 & 63,3 \\
\hline & Cukup (56-75\%) & 7 & 23,3 \\
\hline & Kurang $(<56 \%)$ & 4 & 13,3 \\
\hline \multirow{3}{*}{$\begin{array}{l}\text { 7. Peran Bidan dalam Konseling Awal Kontrasepsi } \\
\text { Suntik DMPA }\end{array}$} & Baik (76-100\%) & 21 & 71,1 \\
\hline & Cukup (56-75\%) & 6 & 21,7 \\
\hline & Kurang $(<56 \%)$ & 3 & 7,2 \\
\hline
\end{tabular}

Sumber: Data Primer, diolah 2012

70\%.Peran bidan menjelaskan alat kontrasepsi pilihan klien dalam kategori baik yaitu 60\%. Peran bidan menjelaskan kunjungan ulang dalam kategori baik yaitu $63,3 \%$. Setelah dirata-rata peran bidan dalam konseling awal kontrasepsi suntik DMPA yaitu dengan kategori baik yaitu 71,1\%, kategori cukup $21,7 \%$, dan kategori kurang $7,2 \%$.

\section{Analisis Data Kualitatif}

Analisis data kualitatif dilakukan untuk memperkuat hasil analisis data kuantitatif. Berdasarkan hasil wawancara dengan 2 responden yang melakukan kunjungan awal didapatkan hasil mengenai peran bidan dalam konseling awal kontrasepsi suntik DMPA yaitu: menyapa dan mengucapkan salam, menanyakan informasi klien, menguraikan informasi alat kontrasepsi pilihan klien, membantu klien menentukan pilihannya, menjelaskan secara lengkap alat kontrasepsi pilihan klien dan membuat kunjungan ulang.

\section{Menyapa dan Mengucapkan Salam}

Adapun ungkapan informan sebagai berikut: “... bu bidan menyapa saya waktu itu... bidannya menyapa saya dengan sopan ..." (Informan 1)

\section{Menanyakan Informasi Klien}

Adapun ungkapan informan sebagai berikut : “...ada informasi yang ditanyakan waktu ... yang ditanyakan umur saya, pekerjaan saya dan suami, terus saya pernah hamil dan bersalin berapa kali..." (Informan 2)

\section{Menguraikan Informasi Alat Kontrasepsi Pilihan Klien}

Adapun ungkapan informan sebagai berikut :

“...ada informasi kontrasepsi suntik... bu bidan menjelaskan alat kontrasepsi yang tersedia seperti suntik KB 3 bulan, lalu dijelaskan keuntungan dan efek sampingnya..." (Informan 2)

\section{Membantu Klien Menentukan Pilihannya}

Adapun ungkapan informan sebagai berikut :

“...bu bidan membantu saya untuk memilih alat kontrasepsi dan memantapkan pilihan saya... bu bidan bertanya alat kontrasepsi yang saya inginkan, lalu bertanya apakah suami saya mendukung saya apabila saya memakai suntik..." (Informan 1)

\section{Menjelaskan Secara Lengkap Alat Kontrasepsi Pilihan Klien}

Adapun ungkapan informan sebagai berikut :

“...tidak semua dijelaskan oleh bu bidan... karena saya tidak tahu siapa saja yang boleh pakai suntik KB 3 bulanan..." ( Informan 2) 


\section{Membuat Kunjungan Ulang}

Adapun ungkapan informan sebagai berikut :

“...bu bidan membuat kunjungan ulang buat saya... saya diberi tahu jadwal untuk kontrol sesuai tanggal yang sudah dituliskan..." (Informan 1)

Berdasarkan tabel 2 setelah dirata-rata peran bidan dalam konseling awal kontrasepsi suntik DMPA yaitu dengan kategori baik adalah $71,1 \%$, kategori cukup $21,7 \%$, dan katgori kurang $7,2 \%$. Dari data tersebut sebagian besar bidan mempunyai peran baik dalam konseling awal kontrasepsi suntik DMPA.Peran bidan dalam konseling awal sangatlah penting karena membantu pasien untuk mengambil keputusan yang tepat dalam memilih alat kontrasepsi. Para bidan diharapkan memiliki teknik saat melakukan konseling, yaitu cara memberikan dukungan, kesempatan kepada klien untuk mengungkapkan perasannya, membuat SIMPULAN dari perassan klien yang tersirat, dan memberikan semua informasi yang dibutuhkan oleh klien ${ }^{8}$.

Pendekatan-pendekatan yang dapat dilakukan bidan dalam konseling adalah pendekatan kognitif dan behavioral.Pada pendekatan kognitif bidan menekankan pada berfikir rasional tentang sesuatu yang dihadapi oleh klien.sedangkan pendekatan behavioral menekankan pada prosedur untuk memfasilitasi perubahan perilaku klien ${ }^{9}$.

Seseorang berperilaku karena pengetahuan yang diperoleh dari pengalaman sendiri atau pengalaman orang lain ${ }^{10}$. Tingkat pengetahuan tenaga kesehatan tentang kontrasepsi suntik DMPA berhubungan signifikan dengan kemampuan dalam memberikan konseling awal pada ibu yang akan melakukan suntik DMPA. Berdasarkan hasil kuesioner yang dibagikan di Puskesmas Mergangsan Yogyakarta dinyatakan bahwa sebagian besar peran bidan adalah baik $(71,1 \%)$. Hal tersebut disebabkan karena tingkat kemampuan bidan dalam konseling awal kontrasepsi suntik DMPA dipengaruhi oleh tingkat pengetahuan.Jika peran bidan kurang dikhawatirkan klien tidak puas terhadap pilihannya dan konsep yang salah tentang alat kontrasepsi tidak diklarifikasi oleh bidan.

Evaluasi di poliklinik RCSM Jakarta pada periode Januari sampai Mei tahun 2000 Pada kontrasepsi metode injeksi, penghentian penggunaan ditemukan pada $50 \%$ akseptor pada tahun pertama. Penyebab terbanyak penghentian tersebut adalah gangguan siklus menstruasi. Keluhan terbanyak adalah perdarahan spotting 29 pasien (78\%), 3 pasien (8\%) datang dengan keluhan pendarahan banyak diluar haid, dan (3\%) pasien dengan keluhan amenorhea sekunder.Gangguan menstruasi yang dialami oleh akseptor kontrasepsi Suntik DMPA sering kali memberikan dampak psikologis dan perasaan khawatir dengan efek samping tersebut, sehingga bidan yang menjelaskan efek samping alat kontrasepsi suntik DMPA pada waktu konseling awal akan mengurangi kekhawatiran dan menambah pengetahuan pasien tentang alat kontrasepsi suntik DMPA $^{6}$.

Peran bidan secara keseluruhan adalah baik, namun yang mempengaruhi penggunaan alat kontrasepsi suntik bukan hanya dari bidan, melainkan dukungan dari suami. Dukungan adalah memberikan dorongan atau semangat dan nasihat kepada orang lain dalam satu situasi pembuatan keputusan ${ }^{11}$. Dukungan suami terhadap istrinya yang menjadi peserta KB dapat memberikan ketenangan sehingga pemakaian lestari.

\section{SIMPULAN DAN SARAN}

Peran bidan dalam menyapa dan mengucap salam saat konseling awal kontrasepsi suntik DMPA di Puskesmas Mergangsan dalam kategori baik yaitu $76,7 \%$, peran bidan saat menanyakan informasi klien saat konseling awal kontrasepsi suntik dalam kategori baik yaitu $83,3 \%$, peran bidan saat menguraikan informasi alat kontrasepsi dalam kategori baik yaitu $73,3 \%$, peran bidan saat membantu klien menentukan pilihan dalam kategori baik yaitu $70 \%$, peran bidan saat menjelaskan alat kontrasepsi pilihan klien dalam kategori baik yaitu $60 \%$, peran bidan saat menjelaskan kunjungan ulang kontrasepsi suntik DMPA dalam kategori baik yaitu $63,3 \%$ dan rata-rata peran bidan dalam konseling awal kontrasepsi suntik DMPA di Puskesmas Mergangsan dengan kategori baik yaitu $71,1 \%$, kategori cukup $21,7 \%$, dan kategori kurang adalah $7,2 \%$.

\section{RUJUKAN}

1. Handayani, S.2010.Buku Ajar Pelayanan KB. Yogyakarta: Pustaka Rihama.

2. BKKBN. 2011. Pencapaian Program Kependudukan dan KB sampai Bulan Desember 2011. Naskah dipresentasikan dalam rapat pengendalian program. Yogyakarta.

3. DepKes RI. 2002. Penyelia Fasilitas Pelayanan Keluarga Berencana. Jakarta: Depkes RI.: 1

4. Sheilla, A. Buku Saku Kontrasepsi dan Kesehatan Seksual Fertilitas Total (TFR). Journal Of Obstetric and Gynaecology Reseach,29. 2000

5. Stalker, P. MDGs. http://www.undp.or.id. 2008. (Diakses 30 Januari 2012) 
6. Billings, E. Metode ovulasi billings. Jakarta: Kepustakaan Populer Gramedia. 2008:23

7. Suyono, H. Bidan Mandiri Sebagai Ujung Tombak Posyandu. http://www.damandiri.or.id. 2007

8. Arum, D.N.S. Panduan Lengkap Pelayanan KB Terkini. Yogyakarta: Mitra Cendikia Press. 2009:42-132
9. Yulifah, R \& Yuswanto, T.J.A. Komunikasi dan Konseling dalam Kebidanan. Jakarta : Salemba Medika. 2009.

10. WHO. Ragam Metode Kontrasepsi. Jakarta: EGC. 2007: 47-114

11. Chaplin. 2002. Kamus Lengkap Psikologi. Jakarta: PT Raja Grafing Hal 